\title{
Why Does Digital Learning Matter? Digital Competencies, Social Justice, and Critical Pedagogy in Initial Teacher Education
}

\author{
Helen Coker \\ Queen Margaret University, Edinburgh
}

\begin{abstract}
Digital tools and spaces are becoming prevalent in schools across the world requiring the development of digital skillsets for student-teachers. Digital technology, in enabling education to extend beyond the space and time boundaries of the conventional classroom (Seifert et. al., 2015), brings the digital landscape into the classroom and firmly into the frame of reference for those preparing student-teachers to enter the profession. For Initial Teacher Education (ITE) programmes which foreground social justice, the digital (i.e., technology which is linked to the internet) goes far beyond a skillset or a discrete subject. Engaging with digital learning encompasses the 21 st century context - both local and global - in which student-teachers and their future pupils are situated. Developing a critical pedagogic approach involves understanding the context in which one lives and enabling learners to challenge or change it (Freire, 1996). For those working in ITE a postdigital lens provides a means to understand the context in which they are situated. Critical pedagogy enables student-teachers to understand that context, and challenge the inequities which persist, preparing them not simply to navigate the digital landscape, but to engage with it critically. Reflecting on student-teacher learning this article explores the digital dimension, highlighting the importance of digital learning when engaging with critical pedagogy and social justice in ITE.
\end{abstract}

\section{Introduction}

The potential to harness technology for education has been re-iterated continually over the last century often as a solution to various educational problems (Lanclos \& White, 2016). As digital tools and spaces become prevalent in all areas of daily life the importance of developing digital 
skills is foregrounded. Ensuring that pupils leave the education system with digital skills and competencies is increasingly a requirement of society as many services move online (Citizens Advice Scotland [CAS], 2018). In Scotland those who are most likely to be digitally excluded are the same households who are also most likely to be identified as disadvantaged or excluded according to a range of other socioeconomic indicators" (White, 2016, p. 5). In Europe, 40\% of citizens were observed to lack digital skills in 2016; of that $40 \%, 42 \%$ were unemployed (European Commission, 2016). Digital exclusion - in terms of both access to the internet and the skills to use digital tools - is a 21st century issue. Increasingly services and employment opportunities require either (or both) access to digital platforms and the skills to use them (CAS, 2018).

Initial teacher education (ITE) prepares students for entry into the teaching profession, ensuring they have the skills and competencies required to teach the future generation and enable their future pupils to prosper in the global context of the 21 st century. Digital skills are a key aspect of this context being "vital for learning, life and work in an increasingly digitised world" (The Scottish Government, 2016). Most European countries include digital skills or competencies in their school curriculum (European Commission, 2019). The terms used for digital learning in this context vary: digital skills, digital competencies, digital literacies, digital education. However, they all denote that the digital aspect of school is no longer a discrete subject and permeates teaching and learning across the curriculum. Student-teachers are required to engage with the digital regardless of their subject specialism or the age of their pupils. Reflecting this, two thirds of European countries include digital skills in the general set of competencies teachers require, and student-teachers must evidence to enter the profession (European Commission, 2019). The development of digital skillsets and the use of educational technology in schools is also seen as a lever for equity. Digital technology can help to close the poverty related attainment gap (The Scottish Government, 2016) and has the "ability to level the field of opportunity for students" (U.S. Department of Education \& Office of Educational Technology, 2017, p. 3). For studentteachers the digital relates not simply to their professional skillset but also to, for what much of the profession would term, the purpose of education.

This article draws on a postdigital perspective to critically reflect on digital learning for student-teachers in the 21 st century context. Drawing on social justice and critical pedagogy it highlights why digital learning is a key consideration for ITE. Digital spaces refer to the online context of the internet or world wide web and digital tools denote the range of devices (e.g., mobile phones, tablets, computers, watches, etc.) which provide access to the internet.

\section{Social Justice and ITE}

In Scotland, social justice is regarded as a key priority for education (Arshad, 2018). For studentteachers it provides a lens through which they can examine their practice. In the 2012 iteration of the Scottish teaching standards (General Teaching Council for Scotland [GTCS], 2012) social justice was positioned as a key value for the teaching profession. For student-teachers in Scotland engaging with social justice is a key aspect of their professional development. It features in the teaching standards at all levels (GTCS, 2012), forming a key aspect of continuing professional development for teachers throughout their careers. It is defined as:

- Embracing locally and globally the educational and social values of sustainability, equality and justice and recognizing the rights and responsibilities of future as well as current generations. 
- Committing to the principles of democracy and social justice through fair, transparent, inclusive and sustainable policies and practices in relation to: age, disability, gender and gender identity, race, ethnicity, religion and belief and sexual orientation.

- Valuing as well as respecting social, cultural and ecological diversity and promoting the principles and practices of local and global citizenship for all learners.

- Demonstrating a commitment to engaging learners in real world issues to enhance learning experiences and outcomes, and to encourage learning our way to a better future.

- Respecting the rights of all learners as outlined in the United Nations Convention on the Rights of the Child (UNCRC) and their entitlement to be included in decisions regarding their learning experiences and have all aspects of their well-being developed and supported. (GTCS, 2012)

The digital context of the 21 st century permeates this definition. If digital learning encompasses learning about the digital, as well as learning how to use it, sustainability is foregrounded. The human and ecological costs of the infrastructure which produces digital technology are issues of sustainability:

The digital is firmly rooted in the material world drawing nourishment in the form of earthly raw materials such as gold, copper and tin (often painstakingly retrieved and assembled by low-wage workers or even children) and with electrical power pumping through its veins drawn from the burning of fossil fuels. (Jandric, 2018, p. 168).

The infrastructure required to maintain digital connectivity and the production of digital tools require material products and labour. With increased capacity comes the need for more servers to host the cloud and these are very much material, even though the language we use to describe data storage suggests otherwise. Digital technology has a human and ecological cost (Knox, 2019) which for future generations are likely to be issues of environmental, societal and economic sustainability. For student-teachers sustainability is a key issue and often it is the environmental or ecological aspects which are their initial frame of reference. Climate change, plastic pollution and cotton production may soon be explored alongside the infrastructure which supports digital tools and spaces.

Democracy, respect, global citizenship and real-world issues play out in a digital context as digital "technology is already embedded in, and entangled with, existing social practices and economic and political systems" (Knox, 2019, p. 3). Communities at global and local levels interact online. Student-teachers need to prepare pupils to interact, communicate and engage in digital spaces, digital spaces which are susceptible to manipulation. Democracy, respect and global citizenship play out in spaces which are influenced by filter bubbles which distort people's perception (Berners-Lee, 2014). Algorithms utilize big data to inform decision-making which reflects human bias rather than objectivity (Tufekci, 2016). The corporate manipulation of big data is well-documented (Bollier, 2010). The digital spaces in which student-teachers and their future pupils engage are not equitable, or widely understood. What do democracy, respect and global citizenship look like in the digital context of the 21st century? The rights of children and young people - their learning and well-being - are situated in a context where digital technology and media are no longer "separate, virtual, 'other' to a 'natural' human and social life (Jandrić et. al., 2018, p. 893). Digital tools enable greater connections as people can access global digital spaces, but it is people who build, code and use them (Cormier et. al., 2019), people who in the future will be educated by the student-teachers of today. 
Access to the internet, which increasingly is required to participate in political debate, to access health care and other services is not equitable. Socio-economic and geographic factors exclude proportions of society, opening up digital divides (CAS, 2016, Philips et. al., 2015, White, 2016). Student-teachers awareness of the equity of access to digital spaces is important in a world which is becoming increasingly digitized. In a context where "for many children digital devices and the possibilities they enable are threaded through everyday life from the earliest days, and their early experiences and understandings are patterned by technology use" (Burnett, 2016, p. 3), understanding the inequities related to technology use is important. Cheaper devices often include more adverts and in-app purchases. Broader inequities linked to gender, ethnicity, and income continue to impact pupils' experiences throughout school (Burnett, 2016). If teachers are to demonstrate "a commitment to engaging learners in real world issues to enhance learning experiences and outcomes, and to encourage learning our way to a better future" (GTCS, 2012), then digital learning is a key aspect of student-teachers professional repertoire. To develop understanding of this context and understand the implications for social justice and equity, a postdigital framing enables critical consideration of these factors.

The concept of the postdigital provides a frame of reference for the 21 st century context in which the digital is not distinct or separate from other aspects of life. It enables student-teachers to develop critical understanding of digital spaces positing that there is no longer a clear definition between what is digital and what it is not. In education digital tools and spaces have been largely perceived as an addition to the pure "human relationships between teachers and their students, or amongst constructivist social groupings" (Knox, 2019, p. 2), an addition, supplement, or enhancement to the human interactions in which the actual work of education happens. In reality, the divide between digital and non-digital is contested; digital technologies and practices have permeated education (Fawns, 2019) as they have all aspects of our lives. They both shape, and are shaped by, our interactions. Lessons are influenced by the digital, even when they do not utilize digital tools, as "digital technologies and the Internet shift not only what happens before and after the formal lesson, but the way students engage with information during class" (Fawns, 2019, p. 133). As digital devices, platforms, and communications become ubiquitous in society pupils current and future experience will be deeply intertwined with the digital (Jandrić et. al., 2018). For many children, teenagers, and adults, digital technology provides communication channels which are utilized daily, they are not a supplement to their interactions with each other, they are part of them.

A postdigital frame enables digital learning to be seen in relation to the role of digital tools and spaces in the lives of student-teachers and their pupils. Digital spaces and tools are not separate from practice, or from issues of social justice, they are intertwined and part of the 21st century global context in which student-teachers must both practice and enable their pupils to live and work. Many pupils are engaged with digital home and social lives as they interact through connected gaming platforms and social media. Education has a role to play in supporting and enabling pupils as they navigate this digital landscape, finding new ways to create identities, and to be agentive (Arndt et. al., 2019), and in ensuring they are confident, safe and discerning users of digital technologies" (Burnett, 2016, p. 3). A postdigital lens challenges the separation of pedagogy and technology and highlights the importance of taking a critical approach to the digital context, while acknowledging that it is now intertwined with and embedded in, our daily practice. 


\section{Twenty-First Century Learning and Critical Pedagogy}

The digital context, and the ways in which pupils and students engage with it permeates all levels of education. An often-heard lament when we are marking assignments at the end of the university term is that students refer to low quality websites rather than the designated reading on a certain topic. Even though a multitude of peer-reviewed journals are available, and textbooks can be accessed online, we still find essays referring to poor quality and often mis-informed websites. The new information society with its ubiquity of technology provides instant access to information (Carrion, 2012). Students engagement with that information is something educational institutions are at once celebrating and lamenting. Access to global perspectives on a chosen discipline opens up the world: using the first website that comes up on a Google search closes it down. Utilizing digital tools for educational purposes requires a skillset beyond the basic skills to operate the tools. The internet is permeated with filter bubbles (Berners-Lee, 2014) and data mining (Bollier, 2010) which are designed to close down the user experience for commercial and sometimes political purposes. Education seeks to open the world up, engage pupils and students with different perspectives. The skillset student-teachers (and pupils) require extends a discerning approach to the information presented and includes awareness of the sources and purposes of information in digital spaces. Editors, publishers, and librarians filter the books found in university and school classrooms and libraries. Online, this needs to be done by the individuals reading the information.

Various models and frameworks for digital literacies, skills and competencies have emerged, foregrounded as an important aspect of 21 st century learning. Nichols and Stornaiuolo (2019) suggest current conceptions focus on users, content and technologies as key dimensions of digital literacy, while the dimensions of governance, ownership and business lurk in the shadows. Tracing the history of the concept they frame digital literacy as an assemblage, suggesting that the concept will continue to emerge as the challenges of the 21 st century unfold (Nichols \& Stornaiuolo, 2019). Given the global events of the current pandemic this seems very likely. A postdigital lens enables critical engagement with all the dimensions, including those lurking in the background. The development of digital competency frameworks for ITE now include consideration of legal and ethical frameworks, privacy and security, and attitudes towards technology (Falloon, 2020). While digital skillsets are an important aspect of student-teacher learning, the frameworks themselves can be critiqued, and as understanding of the role of the digital in society, evolves will continue to develop. A postdigital lens ensures that the function and influence of digital tools and spaces is critically engaged with rather than simply accepted.

Critical pedagogy enables ITE to engage critically with the digital, opening up discussions across the dimensions, rather than focusing on the development of a discrete set of skills. For student-teachers, critical pedagogy enables a deeper understanding of the context in which they are preparing to practice and empowers them to engage with the digital context beyond evidencing a digital skillset, engaging with the factors which will influence the equity of opportunity available to their future pupils. Critical pedagogy is closely linked to the concept of the postdigital in seeking to critically engage with the world (Arndt et. al., 2019). It provides a lever to engage with the digital landscape and ensure that future generations harness its democratic and participatory potential.

\section{So Why Does Digital Learning Matter?}

Digital learning for student-teachers goes far beyond the development of a discrete set of digital skills. It relates to social justice, professional values and the purpose of education. Highlighting 
the ubiquity of the digital in daily life places digital learning firmly within the educational practices of ITE. As Giroux (2015) states, "any discussion of pedagogy must begin with a discussion of educational practices, as a particular way to organize identity, knowledge, place, worth, and meaning" (Giroux, 2015, 22.18-22.23). In the 21 st century, new challenges are emerging for young people as they develop identities in a connected world. For student-teachers the development of their teaching identity can be influenced by participation in online communities of practice or on social media as well as through school and university interactions and activities. Engaging with social justice as a lens for understanding equity in the classroom involves critical engagement with the digital and informs their developing identity as they engage with the values of their future profession. Their future identity as a teacher is grounded in perceptions of the purpose of education and the impact practice will have on pupils' lives, lives which engage in the "'messy realities' (Selwyn, 2010, p. 70) of technology-related practices" (Fawns, 2019, p. 138).

The internet provides a vast resource for constructing knowledge as information can be accessed immediately using digital tools which access global content. Online texts and resources are common aspects of the university experience for student-teachers. Information is no longer confined to university libraries where books and manuscripts are edited, sorted and filtered by librarians and academics. Student-teachers can access educational policies and initiatives from around the world and compare them with those enacted locally. They have access to global content where information is seemingly boundless. But it can also be unfiltered and unedited. Teachers have identified the proliferation of digital information as a potential barrier to professional learning due to the time required to sort and filter it (Coker, 2019). For student-teachers, developing a discerning approach to online information is important. The skills to sort, filter and engage discerningly with online information, are a key requirement both for their own professional learning and for their future pupils.

Digital spaces remove physical and temporal boundaries redefining the places in which student-teachers are situated. With constant access to digital tools the boundaries between work and home, social and professional life can be challenged. Digital learning often shifts the responsibility for creating boundaries to the individual (Coker, 2016). Student-teachers can access course content from anywhere at any time. Engagement is no longer contained within the physical boundaries of the university or school building, or the temporal boundaries of a timetable. With teacher burnout a growing concern (Rajendran et. al., 2020) digital learning also engages with student-teacher wellbeing. Managing workload involves consideration of digital tools and spaces as they blur the boundaries between 'on' and 'off' time. Anywhere, anytime learning can become everywhere, all-the-time. As student-teachers develop their professional skills self-organization and efficacy are influenced by the digital spaces in which they interact and tools they use. Their identity also plays out in digital spaces with different, but often implicit, rules of engagement when interacting on social media platforms, which are utilized for professional as well as personal discourses.

The digital tools and spaces which we use should be interrogated in terms of worth and meaning, what is valued and whose voices are heard? When we use digital tools and spaces to teach how much is our practice being shaped by the coding which has created them: "technology and pedagogy drive each other, caught in a continuous feedback loop" (Fawns, 2019, p. 134). Critical pedagogy enables interrogation of educational practices enabling student-teachers to understand the wider digital context of the 21st century, in which they are preparing pupils to interact, engage and flourish. Further research on this aspect of student-teacher learning would support the enactment of critical pedagogies for the 21 st century. 
level text Times New Roman, 12 point font justified. First level text Times New Roman, 12 point font justified. First level text Times New Roman, 12 point font justified. First level text Times New Roman, 12 point font justified. First level text Times New Roman, 12 point font justified. First level text Times New Roman, 12 point font justified. First level text Times New Roman, 12 point font justified. First level text Times New Roman, 12 point font justified. First level text

\section{Conclusion}

Digital learning is an important consideration at all levels of ITE. It goes beyond including the subject of ICT in the curriculum and beyond the development of a set of digital skills or competencies. Digital learning takes us far beyond the university itself and requires consideration of what digitization means for people living and learning in the 21 st century. Not everyone has the skills or access required to benefit from digitization, gaps in digital equity impact certain sections of society more than others. Issues of sustainability, governance and power lurk in the shadows of digital spaces. The internet, which permeates many peoples' daily lives, has veered away from the open collaborative space imagined by its creator (Berners-Lee, 2014) .

If initial teacher education seeks to engage with social justice, student-teachers' awareness of the role of the digital in society is important. As well as being confident and competent to use digital tools, a critical awareness of the impact of digital spaces on children and young people should be central to student-teacher learning. Applying a postdigital lens suggests all who are involved with the design, development and delivery of teacher education need to consider digital tools and spaces as they are central to both pedagogy and practice in the 21 st century.

\section{References}

Arndt, S., Asher, G., Knox, J., Ford, D.R., Hayes, S., Lăzăroiu, G., Jackson, L., Contreras, J.M., Buchanan, R., D’Olimpio, L., \& Smith, M., (2019). Between the blabbering noise of individuals or the silent dialogue of many: a collective response to 'postdigital science and education' (Jandrić et al. 2018). Postdigital Science and Education, 1(2), 446-474. https://doi.org/10.1007/s42438-019-00037-y

Arshad, R. (2018). Social justice - living the commitment. Teaching Scotland. Retrieved from https://www.gtcs.org.uk/News/teaching-scotland/71-social-justice-living-thecommitment.aspx\#breadcrumb-wrapper

Berners-Lee, T. (2014). A Magna Carta for the web [video]. TED Conferences. Retrieved from https://www.ted.com/talks/tim_berners_lee_a_magna_carta_for_the_web

Bollier, D. (2010). The promise and peril of big data. Washington, D.C.: The Aspen Institute. Retrieved from https://assets.aspeninstitute.org/content/uploads/files/content/docs/pubs/The_Promise_and_Peril_of_Big_Data.pdf

Burnett, C. (2016). The digital age and its implications for learning and teaching in the primary school. York, U.K.: Cambridge Primary Review Trust.

Carrion, R. G. (2012). Out of the Ghetto: Psychological bases of dialogic learning. International Journal of Educational Psychology, 1(1), 51-69. https://doi.org/10.4471/ijep.2012.04 
Citizens Advice Scotland (CAS). (2018). Disconnected understanding digital inclusion and improving access. Retrieved from https://www.cas.org.uk/publications/launch-disconnected-understanding-digital-inclusionand-improving-access

Coker, H. (2016). Understanding pedagogic collaboration in online settings [Unpublished doctoral dissertation]. University of Aberdeen, Aberdeen, Scotland.

Coker, H. (2019). Mediating the flow of professional capital: The potential of technology for rural teachers professional learning in Scotland. Australian and International Journal of Rural Education, 29(3), 39-55.

Cormier, D., Jandrić, P., Childs, M., Hall, R., White, D., Phipps, L., Truelove, I., Hayes, S., \& Fawns, T., (2019). Ten years of the postdigital in the 52group: Reflections and developments 2009-2019. Postdigital Science and Education, 1(2), 475-506. https://doi.org/10.1007/s42438-019-00049-8

European Commission. (2016). The digital competence framework for citizens. European Commission. Retrieved from https://publications.jrc.ec.europa.eu/repository/bitstream/JRC106281/webdigcomp2.1pdf_(online).pdf

European Commission. (2019). Digital education at school in Europe: Eurydice report. Luxembourg: Publications Office of the European Union. Retrieved from https://data.europa.eu/doi/10.2797/66552

Falloon, G. (2020). From digital literacy to digital competence: The teacher digital competency (TDC) framework. Educational Technology Research and Development, 1-24. https://doi.org/10.1007/s11423020-09767-4

Fawns, T. (2019). Postdigital education in design and practice. Postdigital Science and Education, 1(1), 132145. https://doi.org/10.1007/s42438-018-0021-8

Freire, P. (1996). Pedagogy of the oppressed (2nd ed.). New York, NY: Continuum.

Giroux, H. (2015, October 22). Where is the outrage? Critical Pedagogy in Dark Times [Video]. YouTube. Retrieved from https://www.youtube.com/watch? $v=C A x j 87 R R t s c$

General Teaching Council for Scotland [GTCS]. (2012). General Teaching Council for Scotland Teaching Standards. Retrieved from https://www.gtcs.org.uk/professional-standards/standards-for-registration. aspx

Jandrić, P., Knox, J., Besley, T., Ryberg, T., Suoranta, J., \& Hayes, S. (2018). Postdigital science and education. Educational Philosophy and Theory: Critical Pedagogies and Philosophies of Education, 50(10), 893-899. https://doi.org/10.1080/00131857.2018.1454000

Knox, J. (2019). What does the 'postdigital' mean for education? Three critical perspectives on the digital, with implications for educational research and practice. Postdigital Science and Education, 1(2), 357-370. https://doi.org/10.1007/s42438-019-00045-y

Lanclos, D., \& White, D. (2016, September 8). Being human is your problem [Video]. YouTube. Retrieved from https://www.youtube.com/watch?v=OUw0RKDiWHE

Nichols, T. P., \& Stornaiuolo, A. (2019). Assembling "digital literacies": Contingent pasts, possible futures. Media and Communication, 7(2), 14-24. https://doi.org/10.17645/mac.v7i2.1946

Philip, L. J., Cottrill, C., \& Farrington, J. (2015). 'Two-speed' Scotland: Patterns and implications of the digital divide in contemporary Scotland. Scottish Geographical Journal, 131(3-4), 148-170. https://doi.org/10.1080/14702541.2015.1067327

Rajendran, N., Watt, H. M., \& Richardson, P. W. (2020). Teacher burnout and turnover intent. The Australian Educational Researcher, 1-24. https://doi.org/10.1007/s13384-019-00371-X

The Scottish Government. (2016). Enhancing Learning and teaching through the use of digital technology: A digital learning and teaching strategy for Scotland. Edinburgh, Scotland: The Scottish Government. Retrieved from https://www.gov.scot/publications/enhancing-learning-teaching-through-use-digitaltechnology/

Seifert, T., Sheppard, B., \& Wakeham, M. (2015). Teachers' ideas about learning, their use of technology and learner-centred classrooms. European Journal of Open, Distance and E-Learning, 18(2), 64-83.

Tufekci, Z. (2016, June). Machine intelligence makes human morals more important [Video]. Retrieved from https://www.ted.com/talks/zeynep_tufekci_machine_intelligence_makes_human_morals_more_important ?language $=$ en 
U.S. Department of Education \& Office of Educational Technology. (2017). Reimagining the role of technology in education: 2017 national education technology plan update. Washington, D.C.: U.S. Department of Education. https://tech.ed.gov/files/2017/01/NETP17.pdf

White, D. (2016). Digital participation and social justice in Scotland. Carnegie UK Trust. https://d1ssu070pg2v9i.cloudfront.net/pex/carnegie_uk_trust/2016/09/v3-2697-CUKT-DigitalParticipation-summary.pdf 